\title{
Pengaruh pendidikan kesehatan terhadap sikap dan praktik pada pertolongan pertama penanganan luka bakar
}

\author{
Risa Herlianita1*, Chairul Huda Al Husna1', Faqih Ruhyanudin1, Indri Wahyuningsih¹, Zaqqi Ubaidillah', \\ Ahmad Try Theovany², Yunika Era Pratiwi²*
}

1Program Studi Ilmu Keperawatan Universitas Muhammadiyah Malang

*Email: risaherlianita@umm.ac.id

2Mahasiswa Program Studi IImu Keperawatan Universitas Muhammadiyah Malang

*Email: yunika1998@gmail.com

\begin{abstract}
First-aid management of minor burns: attitude, and practice among high school students
\end{abstract}

Background: Burns have become a global public health problem that cause about 180,000 deaths per year. The majority of burns are 20 years old and most occur at home. One of the efforts to improve public attitudes and practice about burn first aid is to teach first aid techniques when burns occur to students using video media and demonstration methods.

Purpose: To determine the effect of health education on first-aid management of minor burns: attitude, and practice among high school students.

Method: A quasi experimental design with one group pre-posttest. The sample that was used from students of grade X and IX which accounted to 52 High School students on March 2020. The observed variable was the change in student attitudes and practice. The data analysis used the Wilcoxon test with $\alpha=0.05$.

Results: Show that the attitude score obtained was a pre-test score of 32.7, while the post-test score was obtained a score of 98.1 . While the practice obtained an median score of pre-test at 25 and the post-test showed the median score reached 80 . The significance value ( $p$-value) obtained by using Wilcoxon data analysis on attitudes and practice $<0,05$ which means there is an influence of health education on first-aid management of minor burns: attitude, and practice among high school students by using video media and demonstration methods.

Conclusion: There is an evidence influence of health education on first-aid management of minor burns. The advantage of this program to be continued to some other a high school student as part of community services from university staff.

Keywords: First-aid management; Minor burns; Attitude; Practice; High school students

Pendahuluan: Luka bakar telah menjadi masalah kesehatan masyarakat global yang menyebabkan kematian sekitar 180.000 orang per tahun yang diakibatkan oleh luka bakar. Kejadian luka bakar mayoritas berusia 20 tahun dan sebagian besar terjadi di rumah. Salah satu upaya untuk meningkatkan sikap dan praktik masyarakat mengenai pertolongan pertama luka bakar yaitu dengan mengajarkan teknik pertologan pertama saat terjadi luka bakar pada siswa dengan menggunakan media video dan metode demonstrasi.

Tujuan: Untuk mengetahui pengaruh Pendidikan Kesehatan terhadap sikap dan praktik pada pertolongan pertama penanganan luka bakar pada siswa SMA.

Metode: Penelitian quasi eksperimental dengan metode penelitian one grup pre-post test. Sampel yang digunakan siwa kelas X dan IX berjumlah 52 Siswa pada bulan Maret 2020. Variabel yang diamati yaitu perubahan pada sikap dan praktik siswa. Data analisis menggunakan uji Wilcoxon dengan $\alpha=0.05$.

Hasil: Menunjukkan bahwa nilai sikap diperoleh skor pre-test 32.7, sedangkan skor post-test diperoleh skor 98.1 . Sedangkan nilai praktik didapatkan nilai median pre-test sebesar 25 dan saat post-test didapatkan nilai median sebesar 80. Nilai signifikasi ( $p$-value) yang didapatkan dengan menggunakan analisa data Wilcoxon pada sikap adalah $<0.05$ pada sikap dan praktik maka dapat disimpulkan ada pengaruh pendidikan kesehatan terhadap sikap dan praktik pada pertolongan pertama penanganan luka bakar meggunakan media video dan metode demonstrasi. 
Pengaruh pendidikan kesehatan terhadap sikap dan praktik pada pertolongan pertama penanganan luka bakar

Simpulan: Terdapat pengaruh pendidikan kesehatan pada sikap dan praktik siswa SMA dalam pertolongan pertama penanganan luka bakar.

\section{Kata Kunci: Pendidikan kesehatan; Sikap; Praktik; Luka Bakar; Pelajar}

\section{PENDAHULUAN}

Luka bakar telah menjadi masalah kesehatan masyarakat global yang menyebabkan kematian sekitar 180.000 orang per tahun yang diakibatkan oleh luka bakar. Sebagian besar terjadi di beberapa negara yang berpenghasilan rendah serta menengah dan hampir dua pertiganya terjadi di Asia Tenggara dan Afrika. Menurut laporan di tahun 2012-2014 terdapat 3.518 kasus luka bakar. Angka kejadian pada tahun 2012 sejumlah 1.187 kasus, pada tahun 2013 menurun menjadi 1.123 kasus dan meningkat pada tahun 2014 terdapat 1.209 kasus. Pravelensi tertinggi luka bakar terdapat di provinsi Papua $(2.0 \%)$ dan Bangka Belitung (1.4\%) (Departemen Kesehatan Republik Indonesia, 2013). Kejadian luka bakar mayoritas berusia 20 tahun dan sebagian besar terjadi dirumah (Rahayuningsih, 2012). Individu dewasa yang berusia 65 tahun dan lansia juga rentan terjadi cedera luka bakar. Individu dewasa terjadi cedera luka bakar diakibatkan merokok sembarangan, disabilitas fisik dan jiwa, dan intoksikasi alkohol. Sedangkan lansia terjadi cedera luka bakar diakibatkan air panas dikarenakan kulit lansia jauh lebih tipis (LeMone et al., 2015).

Adapun perkembangan manajemen tentang pertolongan pertama luka bakar di masyarakat menggunakan pasta gigi dan ramuan lainnya yang dioleskan pada area luka yang dapat dipercaya dapat mengurangi dampak serta memberikan rasa dingin pada luka tersebut, tetapi setelah di teliti di Germany, ternyata membuat semakin buruk dan memperluas luka. Penggunaan air mengalir setelah terjadinya luka bakar dapat menurunkan pelebaran luka bakar (Wood et al., 2016). Sedangkan menurut laporan badan penelitian dimana usia 5-14 tahun rentan mengalami cedera luka bakar. Di lingkungan sekolah sering terjadi cedera dimana anak menghabiskan waktu di sekolah dan ketika anak bermain baik di sengaja maupun tidak dapat berisiko mengalami cedera (Lubis, Hasanah, \& Dewi, 2015; Badan Penelitian dan Pengembangan Kesehatan Kemenkes Republik Indonesia, 2013)
Pendidikan kesehatan merupakan konsep pendidikan yang diterapkan dalam bidang kesehatan. Kegiatan ini dilakukan dengan cara menyebarkan pesan serta menanamkan keyakinan agar masyarakat mengerti dan bisa melakukan suatu perintah yang berhubungan dengan kesehatan dengan tujuannya dapat mengubah perilaku individu dan masyrakat yang tidak sehat menjadi sehat (Notoatmodjo, 2010).

Pemberian pendidikan kesehatan kepada siswa menengah ideal diberikan pendidikan kesehatan yang baik dan benar sehingga mampu mengubah sudut pandang dan bisa di sebarkan kepada keluarga, teman dan masyarakat. Adapun pemberian pendidikan kesehatan meggunakan media video dan demonstrasi dinilai efektif dan sangat aplikatif dalam meningkatkan pemahaman siswa karena media video dengan usia remaja yang lebih suka dijelaskan secara langsung serta menggunakan metode demostrasi yang melibatkan semua responden untuk aktif dalam kegiatan sehingga mempengaruhi sikap secara langsung, dikarenakan menggunakan media pembelajaran dapat memperjelas penjelasan agar tidak terlalu verbal (Mardika, 2019).

Sikap adalah kesiapan untuk merespon suatu rangsangan dengan cara tertentu yang tertutup dan tidak bisa dilihat secara langsung. Sikap ialah konsep pada psikologi sosial yang dibahas unsur sikap yang baik sebagai individu maupun kelompok (Notoatmojo, 2010). Ada beberapa faktor yang dapat mempengaruhi sikap di antaranya yaitu dipengaruhi oleh pengalaman dan cara pandang yang baik, selain itu melibatkan faktor pendapat yaitu emosi yang bersangkutan seperti setuju-tidak setuju, senang-tidak senang, baik-tidak baik. Oleh sebab itu dengan indikator setuju-tidak setuju untuk sikap harus sejalan dengan pengetahuan dengan diberikan pendidikan kesehatan sehingga dapat menimbulkan sikap yang baik (posistif) (Wawan \& Dewi, 2016).

Pertolongan pertama sangat penting untuk dilakukan tindakan pada para korban dengan kasus darurat, dikarenakan keadaan darurat terus meningkat, maka sangat penting untuk kita

Risa Herlianita", Chairul Huda Al Husna', Faqih Ruhyanudin', Indri Wahyuningsih', Zaqqi Ubaidillah', Ahmad Try Theovany ${ }^{2}$, Yunika Era Pratiwi ${ }^{*}$

'Program Studi llmu Keperawatan Universitas Muhammadiyah Malang. *Email: risaherlianita@umm.ac.id

${ }^{2}$ Mahasiswa Program Studi llmu Keperawatan Universitas Muhammadiyah Malang. *Email: yunika1998@gmail.com 
Pengaruh pendidikan kesehatan terhadap sikap dan praktik pada pertolongan pertama penanganan luka bakar

memahami sikap yang benar saat pertolongan pertama khususnya untuk korban luka bakar yang diperoleh dari proses pembelajaran atau pelatihan khusus seperti penyuluhan serta bisa melalui pendidikan kesehatan agar dapat dilakukan sesuai standard operasional yang baik dan benar dalam melakukan pertolongan pertama (Thygerson, 2009).

Masih maraknya pengetahuan perihal penanganan luka bakar menggunakan ramuan atau pasta gigi yang dioleskan pada luka bakar yang dipercaya akan mengurangi dampak dan memberikan sensasi dingin pada daerah yang terluka, dan ternyata setelah diteliti malah memperburuk situasi karena malah memperluas dan tidak menghentikan penyebaran luka bakar (Muthohharoh, 2015). Sedangkan tujuan dari pertolongan pertama luka bakar adalah untuk menghentikan proses pembakaran, mendinginkan pembakaran dan menurunkan rasa sakit. Baik buruknya penanganan luka bakar sangat dipengaruhi oleh tingkat pengetahuan yang dimiliki setiap orang itu sendiri. Semakin baik pengetahuan maka tindakan (praktik) yang akan diambil dan diterapkan semakin baik (Laksmi, 2016). Dalam penelitian telah dipaparkan mengenai penggunaan air mengalir sesaat setelah terjadi luka bakar mampu menurunkan prevalensi atau pelebaran luka bakar (Wood et al., 2016).

Dengan penggalakan promosi kesehatan tentang penatalaksanaan pertolongan pertama pada luka bakar dirasa sangat perlu untuk meningkatkan pengetahuan terutama tentang praktik dan meluruskan adat kuno yang ternyata salah di dalam masyarakat (Murti, 2019). Dengan cara pemberian pendidikan kesehatan kepada remaja usia Sekolah Menengah Atas yang dirasa ideal untuk diberikan pendidikan dan penyuluhan kesehatan mengenai praktik yang baik dan benar tentang pertolongan pertama pada luka bakar karena karakteristik remaja saat ini adalah kurang peduli terhadap kejadian disekitarnya dan juga malas untuk mengingkatkan pengetahuan diri sendiri dan lebih sibuk dengan bermain game di gadget (Muteara, 2016). Sehingga dengan pemberian pendidikan tersebut diharapkan mampu merubah sudut pandang dan disebarluaskan kepada teman sebaya, keluarga dan juga masyarakat yang ada dilingkungannya. kurang, 46-75 adalah cukup serta 76-100 adalah baik.
Dari penelitian-penelitian sebelumnya didapatkan hasil bahwa dengan program intervensi menggunakan air mengalir sesaat setelah terbentuknya luka bakar dan kemudian diberikan Dressing Burn Shield terbukti efektif menurunkan tingkat perluasan luka bakar dan memudahkan bagi tenaga kesehatan untuk menerapkan intervensi lanjutan saat di Rumah sakit (Hamdiya et al., 2015). Pendidikan kesehatan melalui media audiovisual (video) dirasa efektif untuk meningkatkan pemahaman siswa karena faktor usia yang sudah tergolong remaja yang lebih suka dipaparkan melalui penjelasan secara langsung kemudian ditambah dengan metode demonstrasi yang melibatkan seluruh responden untuk berperan aktif dalam kegiatan pendidikan kesehatan sehingga mempengaruhi praktik masyarakat secara langsung, karena penggunaan media pembelajaran dapat memperjelas pemaparan supaya tidak terlalu verbalistik (Wiroatmojo \& Sasonoharjo, 2002).

\section{METODE PENELITIAN}

Metode dalam penelitian ini adalah praeksperimental dengan pendekatan one grup prepost test design dengan sampel sebanyak 52 responden, dan menggunakan teknik total sampling. Surat komisi etik dari KEPK Universitas Muhammadiyah Malang No: E.5.a/068/KEPK UMM/VI/2020.

Pengumpulan data diperoleh dari sumber langsung (data primer dari responden). Sedangkan alat ukur yang digunakan untuk mengumpulkan data berupa kuesioner. Kuesioner yang mengukur sikap menggunakan kuesioner yang dikembangkan oleh Murti (2019). Kuesioner terdiri dari 8 pertanyaan yang terdiri dari 4 skala likert yaitu sangat tidak setuju, tidak setuju, setuju dan sangat setuju. Untuk pertanyaan negative berlaku sebaliknya. Sedangkan untuk mengukur praktik menggunakan lembar checklist yang diadopsi dan dimodifikasi dari Murti (2019) dengan menambahkan beberapa item dari American Burn Association. Lembar checklist terdiri dari 10 pernyataan tindakan dengan klasifikasi apabila tidak dilakukan mendapat nilai 0 , dilakukan namun tidak sempurna diberi nilai 1 , dan apabila dilakukan dengan sempurna diberikan nilai 2. Kemudian dilakukan skoring. penilaian berupa 0-45 adalah

Risa Herlianita ${ }^{*}$, Chairul Huda Al Husna', Faqih Ruhyanudin', Indri Wahyuningsih', Zaqqi Ubaidillah', Ahmad Try Theovany ${ }^{2}$, Yunika Era Pratiwi ${ }^{*}$

'Program Studi llmu Keperawatan Universitas Muhammadiyah Malang. *Email: risaherlianita@umm.ac.id

${ }^{2}$ Mahasiswa Program Studi llmu Keperawatan Universitas Muhammadiyah Malang. *Email: yunika1998@gmail.com 
Pengaruh pendidikan kesehatan terhadap sikap dan praktik pada pertolongan pertama penanganan luka bakar

Kuesioner sikap menunjukkan $r$ tabel 0,396 dan Cronbach's Alpha sebesar 0.722 menunjukkan instrument valid dan reliabel. Sedangkan lembar checklist menunjukkan CVI 0.78 dan Cronbach's Alpha sebesar 0.694 menunjukkan instrument valid dan reliabel.

Pendidikan kesehatan dilaksanakan 3 hari. Responden mendapatkan materi pertolongan pertama luka bakar dari instruktur yang telah bersertifikasi dan juga melihat video pertolongan pertama luka bakar. Setelah itu responden akan melakukan demonstrasi pertolongan pertama luka bakar. Kegiatan tersebut dilaksanakan dalam waktu 60 menit/sesi. Pendidikan Kesehatan dilakukan sebanyak 2 sesi. Masing-masing sesi dihadiri oleh 26 responden. Pelaksanaan posttest dilakukan pada hari ke tiga.

HASIL

Tabel.1 Karakteristik Responden (N=52)

\begin{tabular}{lcc}
\hline Karakteristik & Frekuensi (f) & Persentase (\%) \\
\hline Jenis Kelamin & & \\
Laki-laki & 20 & 38 \\
Perempuan & 32 & 62 \\
& & \\
Usia & 35 & 67 \\
Remaja awal (15-16 tahun) & 17 & 33 \\
Remaja akhir (17-18 tahun) & & \\
\hline
\end{tabular}

Berdasarkan tabel 1 , didapatkan karakteristik jenis kelamin responden yang mayoritas berjenis kelamin perempuan dengan prosentase sebesar $(62 \%)$, berdasarkan karakteristik usia responden sebagian besar berada diusia 16 tahun dengan persentase sebesar (67\%). Didapatkan standar deviasi berjumlah 2,032 yang artinya rata-rata usia responden dalam penelitian ini berada di usia 16 tahun.

Tabel 2. Pengaruh Pendidikan Kesehatan terhadap Sikap dan Praktik ( $\mathrm{N}=52$ )

\begin{tabular}{|c|c|c|c|c|c|}
\hline \multirow[t]{2}{*}{ Variabel } & \multicolumn{2}{|c|}{ Pretest } & \multicolumn{2}{|c|}{ Posttest } & \multirow[t]{2}{*}{$p$-value } \\
\hline & $\begin{array}{l}\text { Frekuensi } \\
\text { (f) }\end{array}$ & $\begin{array}{c}\text { Persentase } \\
(\%)\end{array}$ & $\begin{array}{c}\text { Frekuensi } \\
\text { (f) }\end{array}$ & $\begin{array}{c}\text { Persentase } \\
(\%)\end{array}$ & \\
\hline Sikap & & & & & 0.000 \\
\hline Positif & 17 & 32.7 & 51 & 98.1 & \\
\hline Negatif & 35 & 67.3 & 1 & 1.9 & \\
\hline Praktik & & & & & 0.005 \\
\hline Kurang & 42 & 87.5 & 2 & 4.2 & \\
\hline Cukup & 6 & 12.5 & 21 & 43.8 & \\
\hline Baik & 0 & 0 & 25 & 52 & \\
\hline
\end{tabular}

Berdasarkan data dari tabel diatas menunjukkan bahwa sikap sebelum diberikan intervensi terdapat $(32.7 \%)$ dengan kategori positif dan terdapat $(67.3 \%)$ dengan kategori negatif. Setelah diberikan pendidikan kesehatan menggunakan media video dan metode demonstrasi berubah baik berjumlah (98.1\%) dengan kategori positif dan terdapat $(1.9 \%)$ dengan kategori negatif. Sedangkan praktik siswa menunjukkan bahwa sebelum diberikan intervensi menunjukkan sebanyak 42 responden (87.5\%) dengan kategori kurang, 6 orang responden $(12.5 \%)$ dikategorikan cukup serta tidak ada yang mencapai nilai baik. Setelah diberikan intervensi mengenai pendidikan

Risa Herlianita", Chairul Huda Al Husna', Faqih Ruhyanudin', Indri Wahyuningsih', Zaqqi Ubaidillah', Ahmad Try Theovany ${ }^{2}$, Yunika Era Pratiwi ${ }^{2 *}$

'Program Studi llmu Keperawatan Universitas Muhammadiyah Malang. *Email: risaherlianita@umm.ac.id

${ }^{2}$ Mahasiswa Program Studi llmu Keperawatan Universitas Muhammadiyah Malang. *Email: yunika1998@gmail.com 
Pengaruh pendidikan kesehatan terhadap sikap dan praktik pada pertolongan pertama penanganan luka bakar

kesehatan menggunakan media video dan metode demonstrasi berubah dengan jumlah responden sebanyak 2 orang (4.2\%) dikategorikan kurang, 21 responden (43.8\%) dikategorikan cukup serta 25 responden (52\%) telah dikategorikan baik.

Nilai signifikansi ( $p$-value) yang diperoleh menggunakan analisis data uji Wilcoxon Signed Rank Test dengan nilai $p$-value sebesar 0.000 pada sikap dan 0.005 pada praktik. Data ini menunjukkan arti bahwa terdapat perbedaan yang signifikan antara pre-test sebelum diberikannya pendidikan kesehatan mengenai sikap dan praktik pertolongan pertama luka bakar dan post-test.

\section{PEMBAHASAN}

Penelitian ini menunjukkan adanya pengaruh pendidikan kesehatan mengunakan media video dan metode demonstrasi terhadap peningkatan sikap dan praktik siswa. Sikap ialah respon seseorang terhadap suatu stimulus sehingga tidak dapat terlihat secara langsung (Notoatmojo, 2010). Hasil penelitian ini sejalan dengan teori yang menjelaskan bahwa pendidikan kesehatan mempengaruhi faktor predisposisi yaitu sikap yang dapat mengakibatkan perubahan pada perilaku seseorang (Green, 2005; Nursalam, 2013).

Sedangkan, hasil penelitian sebelumnya menjelaskan bahwa pemberian edukasi atau pendidikan kesehatan menunjukkan sikap positif dalam menangani penanganan luka bakar. Selain itu, sikap positif siswa sekolah jika pelatihan pertolongan pertama diberikan kepada mereka dapat menjadi penyelamat awam yang bertanggung jawab untuk menyelamatkan korban cedera luka bakar, hal ini dikarenakan banyak kejadian cedera luka bakar diluar rumah sakit (Murti, 2019).

Berdasarkan analisa statistik sikap sebelum dan sesudah dilakukan intervensi mengenai pendidikan kesehatan pertolongan pertama luka bakar, peningkatan yang diterima responden dibuktikan dengan meningkatnya sikap. Hal ini sejalan dengan penelitian Aeni et al (2018) berpendapat bahwa nilai terendah 25 dan 95 nilai tertinggi mengambil rata-rata mendapat 76.50. Hal ini menunjukkan bahwa ada pengaruh terhadap intervensi menggunakan media video dan metode demonstrasi terhadap peningkatan sikap siswa SMA terkait pertolongan pertama luka bakar. Begitu juga penelitian yang dilakukan Aeni et al
(2018), hasil penelitian ini menunjukkan sebelum dan sesudah diberikan pendidikan kesehatan dengan menggunakan metode pemutaaran video dan metode demonstrasi terjadi perubahan yang signifikan dengan hasil sebelum dilakukan pendidikan kesehatan dengan metode pemutaran video responden sikap kurang $20(66.7 \%)$ yang menunjukkan perubahan setelah dilakukan intervensi sikap responden baik sebesar $15(50 \%)$.

Dari hasil data penelitian didapatkan hasil bahwa dari 10 tindakan dalam lembar check list didapatkan hasil peningkatan signifikan pada tindakan menyiram area luka bakar dengan air bersih mengalir (bukan air es) selama minimal 5 menit, bahwa sebelum diberikan intervensi dengan nilai 1 sebesar $48 \%$, setelah diberikan intervensi meningkat menjadi $94 \%$ dengan nilai 2 yang artinya dilakukan dengan sempurna. Hal ini disebabkan karena responden telah mendapatkan pendidikan kesehatan dari penelitian. Sesuai dengan penelitian yang sebelumnya bahwa pemberian air mengalir mampu menurunkan suhu pada area luka bakar dan meminimalisir perluasan area luka bakar pada kulit; yang kedua peningkatan signifikan diperoleh pada tindakan mengamankan korban ke area yang aman (Murti, 2019).

Bahwa sebelum pemberian pendidikan kesehatan terdapat nilai 0 dengan persentase $79 \%$ oleh responden. Dan setelah pemberian intervensi meningkat dengan nilai 2 sebanyak $67 \%$. Ini dikarenakan sebelum intervensi para responden tidak menghiraukan keadaan korban saat di lokasi dan lebih fokus kepada luka bakarnya saja. Sependapat dengan penelitian sebelumnya bahwa korban luka bakar harus dijauhkan dari sumber panas terlebih dahulu sehingga tidak membahayakan korban dan juga penolong (Febrina, 2015)

Yang ketiga terdapat peningkatan pada tindakan menutup area luka bakar menggunakan kasa steril/kain bersih dengan balutan longgar. Sebelum diberikannya intervensi nilai responden yang bernilai 1 sebanyak $49 \%$, dan setelah intervensi meningkat menjadi 83\% dengan nilai 2. Ini dikarenakan responden sedikit yang menjawab dengan menutup luka bakar menggunakan kasa steril/kain bersih dan mereka membalutnya dengan kencang, namun setelah intervensi mereka memahami bahwa penting untuk menutup luka

Risa Herlianita ${ }^{*}$, Chairul Huda Al Husna', Faqih Ruhyanudin', Indri Wahyuningsih', Zaqqi Ubaidillah', Ahmad Try Theovany ${ }^{2}$, Yunika Era Pratiwi ${ }^{*}$

'Program Studi llmu Keperawatan Universitas Muhammadiyah Malang. *Email: risaherlianita@umm.ac.id

${ }^{2}$ Mahasiswa Program Studi llmu Keperawatan Universitas Muhammadiyah Malang. *Email: yunika1998@gmail.com 
Pengaruh pendidikan kesehatan terhadap sikap dan praktik pada pertolongan pertama penanganan luka bakar

bakar dengan kasa steril maupun kain bersih dengan balutan longgar dikarenakan untuk mengurangi hinggapnya bakteri dan dengan balutan longar akan membantu mempercepat penyembuhan luka bakar.

Dengan adanya pendidikan kesehatan pertolongan pertama luka bakar mampu meningkatkan praktik dari responden sesuai dengan teori perilaku (praktik). Dengan pemberian pendidikan kesehatan akan mempengaruhi pengetahuan perihal tindakan yang sesuai atau tepat yang akan dilakukan, kemudian akan mempengaruhi sikap yang diartikan sebagai pedoman atau respon terhadap suatu peristiwa atau kejadian dan yang terkhir akan mempengaruhi perilaku (praktik) mengenai tindakan terhadap suatu kejadian yang mungkin akan dialami.

\section{SIMPULAN}

Pemberian pendidikan kesehatan sebelum dan sesudah menggunakan media video dan metode demonstrasi pertolongan pertama luka bakar dapat meningkatkan sikap siswa. Promosi kesehatan digunakan untuk menambah wawasan dan meningkatkan sikap dan praktik yang sesuai rekomendasi kesehatan mengenai pertolongan pertama luka bakar.

\section{SARAN}

Diharapkan perawat dapat memberikan pendidikan kesehatan kepada masyarakat dengan baik menggunakan media video dan metode demonstrasi. Keduanya sangat membantu dalam menyampaikan informasi kesehatan dalam pelaksanaan kegiatan PMR di SMA.

\section{DAFTAR PUSTAKA}

Aeni, N \& Yuhandini D.S. (2018).Pengaruh Pendidikan Kesehatan Dengan Media Video Dan Metode Demonstrasi Terhadap Pengetahuan SADARI.Jurnal Care, 6(2), 162174
Departemen Kesehatan Republik Indonesia (2013). Riset kesehatan dasar. Jakarta: Badan Penelitian dan pengembangan Kesehatan Kementrian Kesehatan RI. Diakses dari: https://depkes.go.id/resources/download/gener al/Hasil\%20Riskesdas\%202013.pdf

Febrina, F. (2015). Proses Penyembuhan Luka Bakar Dengan Gerusan Daun Kedondong (Spondias Dulcis F.) Dan Vaselin Pada Tikus Putih (Rattus Norvegicus) Secara Histopatologi. ETD Unsyiah.

Green, L. W. (2005). Health program planning. An educational and ecological approach

Hamdiya, A., Pius, A., Ken, A., \& Hoyte-williams, P. E. (2015). The trend of acute burns pre-hospital management. Journal of Acute Disease, July, 1-4. https://doi.org/10.1016/j.joad.2015.03.002

Laksmi, I. A. A. (2016). Analisis Korelasi Waktu Pemberian Resusitasi Cairan terhadap Mortalitas Pasien Luka Bakar Berat Fase Emergency. Dunia Kesehatan, 5(2009), 11-14.

LeMone, P., Burke, K. M., \& Bauldoff, G. (2015). Keperawatan Medikal Bedah (5th ed.). Jakarta: EGC.

Lubis, P., Hasanah,O., \& Dewi, A. P. (2015). Gambaran Tingkat Risiko Cedera pada Anak Usia Sekolah (Doctoral dissertation, Riau University).

Mardika, R. (2019). Pengaruh Pendidikan Kesehatan Tentang Bls Menggunakan Media Video Dan Metode Demonstrasi Cpr Terhadap Tingkat Pengetahuan Dan Sikap Siswa Sma (Doctoral dissertation, University of Muhammadiyah Malang).

Risa Herlianita", Chairul Huda Al Husna', Faqih Ruhyanudin', Indri Wahyuningsih', Zaqqi Ubaidillah', Ahmad Try Theovany ${ }^{2}$, Yunika Era Pratiwi ${ }^{2^{*}}$

'Program Studi llmu Keperawatan Universitas Muhammadiyah Malang. *Email: risaherlianita@umm.ac.id

${ }^{2}$ Mahasiswa Program Studi llmu Keperawatan Universitas Muhammadiyah Malang. *Email: yunika1998@gmail.com 
Pengaruh pendidikan kesehatan terhadap sikap dan praktik pada pertolongan pertama penanganan luka bakar

Murti, V. K. (2019). Pengaruh Metode Pendidikan Kesehatan Demonstrasi dengan Media Short Education Movie (SEM) terhadap Perilaku Perawatan Luka pada Anak Usia Sekolah. Universitas Airlangga

Muteara, A. (2016). Perbedaan Efektivitas Media Video dan Teks Card Tentang Basic Life Support Terhadap Perubahan Pengetahuan Remaja Tentang Basic Life Support di SMAN 2 Pamekasan. Universitas Muhammadiyah Malang

Muthohharoh, L. (2015). Gambaran perilaku masyarakat terhadap kejadian luka bakar ringan di perumahan bagasasi cikarang.

Notoatmodjo, S. (2010). Promosi Kesehatan Teori \& Aplikasi. Jakarta: Rineka Cipta.

Nursalam, S. (2013). Metodologi penelitian ilmu keperawatan pendekatan praktis. Jakarta: Salemba Medika.
Rahayuningsih, T. (2012). Penatalaksanaan Luka Bakar. Jurnal Profesi, 8.

Thygerson, A. (2009). First Aid: Pertolongan Pertama Edisi Kelima. Jakarta: Penerbit Erlangga.

Wawan, A., \& Lubis, P., Hasanah,O., \& Dewi, , M. (2010). Teori dan pengukuran pengetahuan, sikap dan perilaku manusia. Yogyakarta: Nuha Medika, 11-18.

Wiroatmojo, P., \& Sasonoharjo.S. (2002). Media Pembelajaran: Bahan ajar diklat kewidyaiswaraan berjenjang tingkat pertama. Jakarta: LAN RI.

Wood, M. F., Phillips, M., Jovic, T., Cassidy, T. J., Cameron, P., \& Edgar, W. D. (2016). Water First Aid Is Beneficial In Humans Post Burn: Evidence from a Bi-National Cohort Study. Retrieved from https://doi.org/10.1371/journa.pone.0147259

Risa Herlianita", Chairul Huda Al Husna', Faqih Ruhyanudin', Indri Wahyuningsih', Zaqqi Ubaidillah', Ahmad Try Theovany ${ }^{2}$, Yunika Era Pratiwi ${ }^{2^{*}}$

'Program Studi llmu Keperawatan Universitas Muhammadiyah Malang. *Email: risaherlianita@umm.ac.id

${ }^{2}$ Mahasiswa Program Studi llmu Keperawatan Universitas Muhammadiyah Malang. *Email: yunika1998@gmail.com 